\title{
Cough in Allergic Rhinitis
}

\author{
Renata Pecova and Milos Tatar \\ Comenius University in Bratislava, Jessenius Faculty of Medicine in Martin \\ Slovakia
}

\section{Introduction}

The diseases of the nose and paranasal sinuses are among the most commonly identified causes of chronic cough (Pratter, 2006). Depending on the population studied and the variations in diagnostic algorithm, the diseases of nose and sinuses are reported to contribute to coughing in $20-40 \%$ of patients with chronic cough who have normal chest radiograph (Chung $\mathcal{E}$ Pavord, 2008). The mechanisms of chronic cough in rhinosinusitis are incompletely understood. Several mechanisms have been proposed, single or in combination: upper airway cough syndrome previously postnasal drip (PND), direct irritation, inflammation in the lower airways and the cough reflex sensitization (Pratter, 2006).

\section{Cough}

Cough has been described as the 'watchdog of the lungs'. Its onset is almost always associated with peripheral stimulation; this is indicative of its reflex character (Korpas $\mathcal{E}$ Tomori, 1979). Cough is mostly an infrequent and physiological act in where its functions are to protect against aspiration and clearing bronchial excretions along with removal of infective and foreign substances that find their way in the respiratory tract. This happens as a reflective act, though cough may also be a voluntary action. When cough occur more frequent and persist, it is usually a cardinal sign of respiratory disease. In this situation protective systems fail or collapse due to overloading of foreign substances or excessive bronchial excretions and to compensate this breakdown cough frequency increases. The action of cough can be divided into three phases: inspiratory, compressive and expulsive (Coryllos, 1937; Korpas $\mathcal{E}$ Tomori, 1979). Cough is a defensive reflex that protects the airways from inhaling potentially damaging particles, aeroallergens, pathogens, aspirate and secretions accumulated (Mazzone et al., 2003). Like any other reflex process, cough is effected by means of a reflex arc, which is composed of five basic links: receptors, an afferent pathway, a centre, an efferent pathway and effectors (Korpas $\mathcal{E}$ Tomori, 1979).

\subsection{Airway afferent and receptors}

The airway afferent nerve fibers may be divided into several subtypes based on their physicochemical sensitivity, adaptation to sustained lung inflation, neurochemistry, origin, myelination, conduction velocity and sites of termination in the airways (Mazzone et al., 2003). The lack of specificity and characteristics for each of these subgroups has made the 
study and to define them separately quite difficult. By gross dividing, however, these physiological and morphological attributes can be used to identify at least three broad classes of afferent nerve fibers: rapidly adapting mechanoreceptors (RARs), slowly adapting mechanoreceptors (SARs) and unmyelinated C-fibers (C-fibers) (Mazzone et al., 2003).

\subsubsection{Rapidly adapting receptors (RARs)}

While the anatomical arrangement of RARs termination is unknown, functional studies suggest that these receptors terminate within or beneath the epithelium and are localized to both intra- and extrapulmonary airways (Bergren E Sampson, 1982; Riccio et al., 1996c, Ho et al., 2001). RARs, as its name implies, is differentiated from the other airway afferent nerves by their rapid (1-2sec) adaptation to sustained lung inflations (Armstrong $\mathcal{E}$ Luck 1974; Coleridge $\mathcal{E}$ Coleridge, 1984; Ho et al., 2001; Sant'Ambrogio \& Widdicombe, 2001; Widdicombe, 2001). Other distinguishing properties of RARs include their sensitivity to lung collapse and/or lung deflation, their responsiveness to alterations in dynamic lung compliance (thus their sensitivity to bronchospasm), and theirs conduction velocity (4-18m/sec), suggestive of small myelinated axons (Bergren E Sampson, 1982; Jonzon et al., 1986; Riccio et al., 1996; Ho et al., 2001; Widdicombe, 2001). Analysis has shown that sustained activation of RARs produced by dynamic lung inflation, bronchospasm or lung collapse is not attributable to an electrophysiological adaptation (Bergren E Sampson 1982; Pack \& DeLaney, 1983; McAlexander et al., 1999; Ho et al., 2001). Maybe a more suitable name for better defining RARs are dynamic receptors that respond to changes in airway mechanical properties (e.g., diameter, length, interstitial pressures).

The dynamic mechanical forces accompanying lung inflation and deflation sporadically activates RARs throughout the respiratory cycle and becomes more active as the rate of lung inflation increase (Pack \& DeLaney 1983; McAlexander et al., 1999; Ho et al., 2001). This means that the RARs activity during respiration is connected to respiratory rate and is higher in small animals, while in larger animals, it would be almost unmeasurable. In the smaller animals, RARs-dependent reflexes will also require a heightened activity in the already active RARs.

Even though RARs may be insensitive to 'direct' chemical stimuli, stimuli from bronchospasm or obstruction due to mucus secretion or oedema can increase the RAR activity (Mohammed et al., 1993; Bonham et al., 1996; Bergren, 1997; Joad et al., 1997; Canning et al., 2001; Widdicombe, 2001). By preventing the local end-organ effects that is stimulated by substances such as histamine, capsaicin, substance $P$ and bradykinin, activation of RARs can be markedly inhibited or abolished (Mazzone et al., 2003). Stimuli that evoke cough react RARs and RARs fullfill many of the accepted criteria for mediating cough (Sant'Ambrogio et al., 1984; Canning et al., 2000; Sant'Ambrogio \& Widdicombe, 2001; Widdicombe 2001). Studies of vagal cooling have shown further evidence of RARs role in the cough reflex, that block cough at temperatures that selectively abolish activity in myelinated fibers (including RARs) while preserving C-fiber activity (Widdicombe, 1974; Tatar et al., 1988; Tatar et al., 1994).

\subsubsection{Slowly adapting stretch receptors (SARs)}

SARs is equal to RARs in at they also are highly sensitive to the mechanical forces lungs deal with during breathing. SARs, however, differentiate from RARs in that their activity increases sharply during inspiratory phase and peaks just before the initiation of expiration (Ho et al., 2001; Schelegle E Green, 2001), while RARs can be activated during both inflation 
and deflation of the lung (including lung collapse) (Ho et al. 2001; Widdicombe, 2003). This makes it likely that SARs are the primary afferent fibers involved in the Hering-Breuer reflex, a reflex which ends inspiration and initiates expiration when the lungs are adequately inflated (Schelegle \& Green, 2001). SARs also adapt more slowly to stimuli from sustained lung inflations, than, as the name implies, RARs demonstrate rapid adaption (Ho et al., 2001; Widdicombe, 2003). SARs may also be differently spread throughout the airways (Schelegle \& Green, 2001).

Evoking of reflexes is also done differently by SARs and RARs. Activation by SARs results in a reduction in airway tone due to inhibition of cholinergic drive to the airway smooth muscle (Canning et al., 2001).

There is suggested after single-unit recordings from the vagus nerve in rabbits that activity of SARs neither increase before or during ammonia-induced coughing (Matsumoto, 1988). Even though this means that RARs do not play any big part in the cough reflex, RARs clear influence over the respiratiory pattern indicates that they do have a role in cough reflex. It is suggested that the usage of the loop diuretic frusemide (furosemide) will increase the baseline acitvity of RARs, and thereby account for the reported antitussive effects of this agent in animal and human subjects. Reports have shown that preloading, in contrast, that likely will increase baseline SARs activity, will increase expiratory efforts during cough (Hanacek $\mathcal{E}$ Korpas, 1982; Nishino et al., 1989). On the contrary, experiments on rabbits inhaling sulfur dioxide have been used in an attempt to selectively block SARs activity show that the cough reflex is coincidentally attenuated (Hanacek et al., 1984, Sant'Ambrogio et al., 1984). This selectivity to sulfur dioxide for airway SARs is however questionable since several reports show that sulfur dioxide has an excitatory action on airway C-fibers (Atzori et al., 1992; Wang et al., 1996).

Studies done on CNS processing has also suggested that cough may be facilitated by SARs. There is proposed that a central cough network in which SARs facilitate cough via activation of brainstem second-order neurons (pump cells) of the SARs reflex pathway (Shannon et al., 1998).

\subsubsection{C-fibers}

C-fibers are unmyelinated afferent fibres which are similar to the unmyelinated nociceptors of the somatic nerve fibers both physiologically and morphologically, and these C-fibers constitute the majority of afferent nerves innervating the airways (Coleridge $\mathcal{E}$ Coleridge, 1984; Ma \& Woolf, 1995; Lee E Pisarri, 2001). Being unmyelinated differ their conduction velocity compared to RARs and SARs, but their relative insensitivity to mechanical stimulation, lung inflation and their responsiveness to bradykinin and capsaicin is also important differentiations (Armstrong \& Luck, 1974; Riccio et al., 1996; Bergren, 1997; Ho et al., 2001; Canning et al., 2001; Lee E Pisarri, 2001; Widdicombe, 2001). C-fibers also differ from the RARs in that bradykinin- and capsaicin-evoked activation of their endings in the airways is not inhibited by pre-treatment with bronchodilators. Oppositely, bronchodilators such as prostaglandin $\mathrm{E}_{2}$, adrenaline and adenosine may enhance excitability of airway afferent $\mathrm{C}$ fibers (Ho et al., 2000; Lee E Pisarri, 2001). By this, C- fibers differentiate from RARs in at their bronchopulmonary C-fibers are directly activated by substances like bradykinin and capsaicin.

Studies on C-fibers has been done on many animals, and morphological studies on guineapigs and rats have shown that $\mathrm{C}$ - fibers innervate the airway epithelium together with 
effector structures within the airway wall (Lundberg et al., 1984; Baluk et al., 1992; Riccio et al., 1996; Hunter \& Undem, 1999). Several studies show a unique neurochemical property of the bronchopulmonary fibers has been used to illustrate the distribution and peripheral nerve terminals of the unmyelinated airway afferent nerve endings. These studies reveal that Cfiber have the ability to synthesize neuropeptides that afterwards are transported to their central and peripheral nerve terminals (Baluk et al., 1992; Riccio et al., 1996c; Hunter \& Undem, 1999; Myers et al., 2002). Coleridge $\mathcal{E}$ Coleridge (1984) described in afferent vagal C-fiber innervations of the lungs and airways and its functional significance, that in dogs C-fibers may be further subdivided into bronchial and pulmonary fibers, a differentiation based on sites of termination and on responsiveness to chemical and mechanical stimuli. Based on this division, pulmonary C-fibers may be unresponsive to histamine, while bronchial Cfibers are activated by histamine. This observation is made on dogs, and in whether the physiologic differences are similar in other species are still unknown, but recent studies have described C-fiber subtypes innervating in the intrapulmonary airways and lungs of mice and guinea pigs (Kollarik et al., 2003; Undem et al., 2003). C-fibers are believed to have an important role in airway reflexes. Even with their polygonal shape that made them respond to chemical and mechanical stimulation, compared to RARs and SARs, the threshold for mechanical stimulation is markedly increased (Matsumoto, 1988; Deep et al., 2001). As a consequence, C-fibers mostly lie latent throughout the respiratory cycle, but are easily activated by chemical stimuli such as capsaicin, bradykinin, citric acid, hypertonic saline, and sulphur dioxide (Riccio et al., 1996c; Ho et al., 2001; Widdicombe, 2001; Lee E Pisarri, 2001). Increased airway parasympathetic nerve activity and chemoreflex, characterized by apnea (followed by rapid shallow breathing), bradycardia, and hypotension are all reflex responses elicited by C- fiber activation (Coleridge $\mathcal{E}$ Coleridge, 1984; Canning et al., 2001). In species like rats and guinea-pigs bronchospasm and neurogenic inflammation by C-fibre activation which elicit peripheral release of neuropeptides via an axon reflex (Barnes, 2001; Lee E Pisarri, 2001).

The function of the C-fibers in the cough reflex is debatable. Many studies have given evidence to the hypothesis that C-fiber activation in the airways precipitate cough. In some cases there is believed that selective stimulants like capsaicin, bradykinin and citric acid evoke cough in conscious animals and humans (Coleridge $\mathcal{E}$ Coleridge, 1984; Forsberg $\mathcal{E}$ Karlsson, 1986; Mohammed et al., 1993; Karlsson, 1996; Mazzone et al., 2002). In addition, capsaicin is used in pretreatment when needed to selectively deplete C-fibers of neuropeptides, which abrogate cough in guinea-pigs induced by citric acid, but by evoking C-fibers by mechanical probing has no effect on cough (Forsberg $\mathcal{E}$ Karlsson, 1986). At last, pharmacological studies that take the advantage of the unique expression of neurokinins by the airway C-fibers, have shown that bradykinin-, citric acid-induced cough in cats and guinea-pigs is attenuated or abolished by neurokinin receptor antagonists (Bolser et al., 1997).

All these evidences above indicate that C-fibers take part in the cough reflex. On the other hand, there are also evidences suggesting that C-fibers do not evoke cough and may instead inhibit cough by stimulation of RARs-fibers. For instance, in studies with anesthetized animals, C-fibre stimulation has consistently failed to evoke coughing, even though cough can be readily induced in these animals by mechanically probing mucosal sites along the airways (Tatar et al., 1988; Tatar et al., 1994; Canning et al., 2000; Deep et al., 2001). Systemic administration of C-fibre stimulants may in fact have been shown to inhibit cough evoked 
by RARs stimulation in various species (Tatar et al., 1988; Tatar et al., 1994; Canning et al., 2000). Further evidence supports the C-fibers role in inhibition of cough in that vagal cooling to temperatures that can maintain C-fiber-dependent reflexes can abolish cough (Tatar et al., 1994).

The reason for these antagonistic evidences about C-fibers and cough are ambiguous. One reason may be that general anesthesia in animals selectively disrupt the ability of C-fibers to evoke cough without unfavourably affecting cough induced by stimulation of RARs. Nishino et al. (1996) studies of cough and the reflexes on irritation of airway mucosa in man show that general anesthesia has a profound influence over cough reflex. But there is unlikely that C-fibre activation and C-fibre-mediated reflex are entirely prevented by anesthesia (Roberts et al., 1981; Coleridge \& Coleridge, 1984; Bergren 1997; Canning et al., 2001). So, action by anesthesias on C-fibers may either work by setting off cough activation by the inhibitory effects of C-fiber or it must selectively inhibit cough-related natural pathways. As an alternative, general anesthesia might actually intervene with the conscious perception of airway irritation and thereby interfere with the subjects urge to cough. One interesting fact of this circumstance is that capsaicin-evoked cough can be consciously suppressed in humans tested (Hutchings et al., 1993) Despite a lot of studies, there is still an equally possible hypothesis that C-fibre stimulation alone is too insufficient to evoke cough but are dependent on the airway afferent interactions in both the periphery and the level of CNS (Canning \& Mazzone, 2005).

\subsection{Central regulation of cough}

Studies have come a long way in understanding the central mechanism involved in cough production. Evidence has shown that a single network of neurons seems to mediate cough as well as breathing (Shannon et al., 1996; Shannon et al., 1997; Shannon et al., 1998; Shannon et al., 2000).

Though, it is obvious that cough and breathing are two different behaviors. It is a process called reconfiguration, in which the same network produces different behaviors that involve dynamic alteration of the excitability of key elements and/or recruitment of previously silent elements. There is suggested that the excitability of this network is additionally controlled by a 'gating' mechanism that is sensitive to antitussive drugs (Bolser et al., 1999).

\subsection{Plasticity}

Coughing is connected with both acute and chronic respiratory diseases such as upper respiratory infections, asthma, gastro-oesophageal reflux (GOR), as well as other more seldom causes. It is likely that the cough arises due to production of various tussigenic agents in the wall of the airway, and increased sensitivity of the cough reflex pathway. Though, the structures involved and the molecular mechanism of the sensitivity is still unknown. Afferent nerves are under constantly changing in structure and activity. Neuroplasticity is the general term to the change in structure and function of nerves (Woolf $\mathcal{E}$ Salter, 2000). Cough plasticity represents the changes in neuronal excitability, receptor expression, transmitter chemistry and the structure of the nerve. Unfortunately, not much is known about the function of vagal nerve plasticity in human disease. Most facts have been collected by using various tissue and animal models in studies on the somatosensory system, and functional and electrophysiological studies of the vagal afferent nerves. 
Clinical studies on cough reflex sensitivity show that it can be quantified by several methods (Pounsford et al., 1985a; Choudry \& Fuller, 1992). Capsaicin and citric acid are the most commonly used tussigenic agent, and their use have expressed that some diseases are associated with an appreciable increase in cough reflex sensitivity. During these studies one must take into consideration that cough reflex hypersensitity may be stimulus specific, and thereby influence the cough sensitivity.

\subsubsection{Molecular mechanisms of increased excitability}

Allergic inflammation or various inflammatory mediators have under scientific level shown to both increase cough reflex sensitivity and excitability of afferent nerves of the airway. For example, in humans $\mathrm{PGE}_{2}$ enhance capsaicin-induced cough (Choudry et al., 1989). It has also been done a large amount of clinical studies that have displayed that certain pathological conditions are accompanied by a considerable increase in cough reflex sensitivity in humans. This is also shown in studies done on animals, for example in guinea-pigs, when allergic inflammation or inhalation of bradykinin potentiated cough was evoked by capsaicin and citric acid (Lii et al., 2001). Studies done in rats have shown that inhalation of inflammatory mediators (also $\mathrm{PGE}_{2}$ and eosinophil major basic protein) follow potentiation of capsaicin-induced action potential discharge in nociceptive fibers in the lungs (Ho et al., 2000). In addition, inflammatory condition enhances the excitability of RARs fibers. As in studies on sensitized guinea pigs trachea was exposed to antigen causing a substantial increase in the mechanosensitivity of RARs fibers (Riccio et al., 1996a). Later, it has been shown that cough may be evoked in all species used in studies by using either chemical stimulation of airway mucosa or by inhalation of acidic saline or capsaicin (Canning, 2008). Besides these studies done, relatively little studies resulting in published articles have occurred relating to the airway afferent excitability and the underlying mechanisms that increases it.

Most of the studies on mechanistic basis of afferent nerve excitability and plasticity have been done on nociceptive-type somatosensory neurons which are isolated from the dorsal root ganglia (Woolf $\mathcal{E}$ Salter, 2000). Somatosensory- and airways nociceptive fibers share many properties and therefore give useful information on how the excitability on the airway nociceptor works. But, one must not exclude the fact that RARs phenotype fibre is not readily analogous to any type of somatosensory afferent. So, still little is known in how the airway RARs excitability is modulated.

\subsubsection{Vanilloid receptor (TRPV1) mechanisms}

Vanilloid receptor now referred to as TRPV1 (previously called vanilloid receptor 1 (VR1)), is of the vagal afferent nociceptors (C-fibers and Aס-fibers) that innervate the airway express the capsaicin receptor, a member of the transient potential family (Riccio et al., 1996b; Fox, 2002). Unfortunately, the extent to which capsaicin can lead to RARs activation in vivo is likely trough indirect means because TRPV1 is not expressed by RAR-type fibers in the airways of guinea-pigs (Myers et al., 2002).

Membrane depolarization is a result of the TRPV1 which work as an ionotropic receptor that when activated serve as a nonselective cation channel leading to depolarization of membrane (Caterina $\mathcal{E}$ Julius, 2001). It is important to know that besides being activated by vanilloid compounds, TRPV1 is also activated by endogenous lipid mediators such as ananamide and arachidonic acid metabolites of various lipoxygenase enzymes (Caterina $\mathcal{E}$ 
Julius, 2001; Shin et al., 2002). Some metabotrophic receptors of TRPV1 may also be activated by intracellular signal transduction mechanism. Studies in both airway afferent fibers and somatosensory neurons indicate the hypothesis that bradykinin can, at least partly, activate sensory nerves through production of lipogenase product of arachidonic acid and subsequent activation of TRPV1 (Shin et al., 2002). One other important fact is the hydrogen ions ability to activate TRPV1 on airway physiology with $\mathrm{pH} \sim 6$ at $37^{\circ} \mathrm{C}$ (Caterina $\mathcal{E}$ Julius, 2001).

TRPV1 also have a distinct characteristic by its ability to integrate different kinds of stimuli, meaning that the action of one TRPV1 agonist potentiates the action of the other (Caterina $\mathcal{E}$ Julius, 2001). TRPV1 have the ability to accumulate in the airway wall during different kinds of pathological condition. As in asthma, the inflammation could, by a decrease of $\mathrm{pH}$ of airway wall, increase the concentration of hydrogen ions, bradykinin and certain lipid mediators.

Increase of TRPV1 conductance secondary to phosholipase C (PLC) activation and subsequent phosphorylation of TRPV1 by protein kinase $C$ (PKC) can be done by agonists of protein G protein-coupled (Gp-coupled) receptors (Premkumar $\mathcal{E}$ Ahern, 2000). This indicates that inflammatory mediators that stimulate classical G-protein-coupled receptors can increase conductance through TRPV1. There are evidence showing that PLC may also release TRPV1 from phosphatidylinositol (Riccio et al., 1996b) and phosphate inhibition (Chuang et al., 2001). This action may take part in increasing the TRPV1 activity after stimulation of nerve growth factor (NFG) of Tyrosine Receptor Kinase A (trk-A) receptors as well as $\mathrm{B}_{2}$-receptors activation by bradykinin.

Gs-coupled receptors may also increase the amplitude of the TRPV1-mediated generator potential. In rats, rising of cAMP increases capsaicin-induced conductance in their nociceptive neurons, an action that may be inhibited by protein kinase A (PKA)-inhibitors (Lopshire $\mathcal{E}$ Nocol, 1998). Further studies also show that in rat pulmonary nociceptors capsaicin-induced action potential discharge is increased by prostaglandin $\mathrm{E}_{2}\left(\mathrm{PGE}_{2}\right)$ (Ho et al., 2000). It is also proven that there is an increase in expression of TRPV1 in rat sensory neurons by neutrophins like NGF (Michael \& Priestley, 1999). Even though it is not made any studies in humans concerning healthy or diseased airways, places of airway inflammation is known to be elevated by nerve growth factors (Virchow et al., 1998). TRPV1 is not the only mechanism that can affect nociceptor excitability. Decrease of threshold for mechanical stimulation of airway afferent nerves have been shown in various inflammatory mediators (Ho et al., 2000; Riccio et al., 1996a). How this is done is still unknown, but studies suggest that it might involve several ion channels and modulation of these.

\subsubsection{Sodium channels}

Voltage-gated sodium channels have the possibility to affect the threshold for action potential generation and peak frequency of action potential discharge both in number and activity. The mammals have abundant of different sodium channels in nerves, and based on their sensitivity to tetrodotoxin (TTE) we divide them into two groups, the TTX-sensitive and TTX-resistant sodium channels. In airway afferent nerves both groups of channels are found (Carr \& Undem, 2001). Of extra interest are the TTX-resistant channel and its ability to regulate excitability of modulation by inflammatory mediators (Gold et al., 1996). Studies made on guinea-pigs and their jugular ganglia showed that most of these nerves have enough TTX-resistant sodium channels to achieve an action potential generation (Christian $\mathcal{E}$ 
Togo, 1995). Even though there still are some questions about the details of the channels function, there are data proving that airway-specific jugular neuronal cell bodies have enough TTX-resistant current to support formation of action potential (Carr E Undem, 2001). Some inflammatory mediators have influence the sodium current. $\mathrm{PGE}_{2}$, adenosine and 5hydroxytryptamine (5-HT) are some mediators that have shown to be able to enhance the TTX-resistant sodium current in somatosensory neurons (Gold et al., 1996). Though, what impact these mediators have are still not established.

\subsubsection{Neurotransmitter plasticity}

Neuropeptides are present both in peripheral and central C-fibers innervating the airways, and substance $\mathrm{P}$ and related tachykinins are the most common neuropeptides, though other peptide are also found there.

An increased production of different types of neuropeptides in inflammatory disease is a typical action, and is proven in animal models and several inflammatory diseases, such as COPD (Tomaki et al., 1995). This action often happens after an increase in expression of preprotachykinin genes in the sensory neurons (Hunter et al., 1998; Fischer et al., 1996). How the signalling occurs is still not known, but neutrotrophins are believed to be involved since they are known to interact with tyrosine kinase-linked receptors (trk receptors) to evoke signals in the cell body. Neurotrophin-trk receptor complexes affect transcriptions of different genes, also those involving neuropeptide synthesis and are likely transported via axonal system from nerve terminals to the cell body (Klesse and Parada, 1999). In the presence of airway inflammation, neurotrophins such as nerve growth factor (NGF) and brainderived neurotrophin factor are rarely found, and production may even be increased (Virchow et al., 1998).

In inflammatory reactions release of neurokinins may cause vasodilatation, plasma extravasation, and even bronchial smooth cell contraction in some species (Advenier $\mathcal{E}$ Emonds-Alt, 1996). These actions have shown in indirectly activate RARs nerves in guineapigs which further participate in tussigenive activity of these agents (Advenier $\mathcal{E}$ Emonds-Alt, 1996; Joad et al., 1997). Neuropeptides are synthesized in body cells, transported to peripheral and central terminals and in central terminals in brainstem they are released after action potential release (Woolf and Salter, 2000). This release in the central terminals is likely to have an essential role in regulating the cough reflex sensitivity. RARs fibers in central neurons have shown in some cases to have a convergence on the same secondary terminals as nociceptive C-fibers (Mazzone $\mathcal{E}$ Canning, 2002). This evidence, and adding the fact those electrophysiological effects on neurokinins on postsynaptic membrane provide the abstract model of the process that is called by scientists "central sensitization"(Woolf \& Salter, 2000). This refers to the action where one type of nerve input, for example nociceptive C-fibre, actually increases the synaptic transmission of another type of input, as in RARs fibers. This may lead to a decrease in the amount of RAR input needed to trigger cough in the CNS.

While older studies suggest that inflammation may cause increase in sensory neuropeptides secondary to induction of preprotachykinin genes in nociceptive neurones, it is now indicated in studies of both somatosensory and vagal sensory systems, that inflammation also may cause phenotypic change in the neuropeptidergic innervation (Neumann et al., 1996; Carr et al., 2002; Myers et al., 2002). Studies of airway afferent neurones in guinea pigs with allergen or virus infection showed increased number of sensory neurokinins (Fischer et al., 1996; Carr et al., 2002; Myers et al., 2002). In response to inflammation there is also 
histologically proved that the neuropeptides produced in this case are also transported to central terminals of the RAR neurons (Myers et al., 2002). This is an important finding which supports the fact that there is a mechanical activation of RARs fibers leading neurokinin release in the brainstem as a response to inflammation from allergy or respiratory virus infection. A neuropeptide innervation of the somatosensory system has been documented where painful sensation has phenotypically shifted to painless stimuli, an action referred to as allodynia (Neumann et al., 1996). From this one could start to wonder if this may have some influence in the extraneous cough sensation that may cause the desire to cough without having any to cough up in the airway.

\subsubsection{Change in nerve fibre density and extraneuronal effects}

The environment causes change in the density of sensory innervation (Stead, 1992). This change due to either growth factor release or tissue damage may lead to nerve fibre growth and fibresprouting, but if this causes an increased sensitivity to cough is still unknown and minimal studies have been done on this topic.

\section{Cough in adults}

European Respiratory Society recommends two possible definitions of cough (Morice et al., 2007): 1) Cough is a three-phase expulsive motor act characterized by an inspiratory effort (inspiratory phase), followed by a forced expiratory effort against a closed glottis (compressive phase) and then by opening of the glottis and rapid expiratory airflow (expulsive phase). 2) Cough is a forced expulsive maneuver, usually against a closed glottis and which is associated with a characteristic sound.

Cough is classified as acute and chronic. This classification is useful clinically, since the etiology of acute cough differs from the etiology of chronic cough. Chronic cough in adults is a cough which persists for over 8 weeks.

\subsection{Acute cough in adults}

Cough is the commonest symptom for which people seek medical advice (Irwin et al., 1993). Lower airway infections are the most common cause of acute cough. Lower airway infections refer to acute tracheobronchitis, acute bronchiolitis and community acquired pneumonia (CAP). Acute tracheobronchitis is mostly viral in origin. Influenza virus, rhinovirus, parainfluenza virus, Respiratory syncytical virus (RSV), adenovirus and coronavirus are the pathogens most commonly associated with acute cough in patients with acute tracheobronchitis. All these viruses have a short incubation period of between one and four days, and all symptoms including cough usually resolves within three weeks (Pek $\mathcal{E}$ Boushey, 2003). Many people with viral cough do not seek medical advice, but treat themselves with over the counter products. This means that there is no sufficient statistical data about the extent of acute cough (Morice, 2003). 5-10\% of all cases with acute tracheobronchitis are caused by bacteria. Among the most common bacterial pathogens are Bordetella pertussis, Mycoplasma pneumoniae, Streptococcus pneumoniae and Chlamydia pneumoniae. CAP is a common cause of hospitalization and death from infectious disease in adults. The etiological agent is identified in only $50 \%$ of all cases. Streptococcus pneumoniae, Haemophilus influenzae and Staphylococcus aureus are among the most commonly identified microbial pathogens that cause pneumonia (Pek E Boushey, 2003). 
The mechanism of cough in lower airway infection is not completely understood. Possible mechanisms have been suggested by Pek E Boushey (2003): 1) Irritation of the nerve endings in the larynx and trachea caused by dripping of secretions containing inflammatory mediators from the nasopharynx into larynx or trachea is one possible mechanism. Exposure of the nerve endings (e.g. RARs) caused by damage and destruction of the airway epithelium is thought to decrease the cough threshold to environmental irritants and inflammatory secretions, thus causing cough. 2) The infection of the airways also leads to accumulation of secretions and debris in the airway lumen. As a result the mechanoreceptors in the bronchial mucosa are activated, triggering cough to clear the airways for the excess secretions and foreign material. 3) Cough may also occur because of stimulation of nerve endings by inflammatory mediators released directly from airway epithelial cells or from inflammatory cells attracted to the site of infection. 4) Neuropeptidases degrade neuropeptides released from adjacent afferent nerve endings. Enhanced effect of neuropeptidases because of decrease in the neutral endopeptidase from epithelial cells is also one possible mechanism triggering cough in lower airway infections.

\subsection{Chronic cough in adults}

The three most common causes of chronic cough are asthma bronchiale, GERD and chronic upper airway syndrome (CUAS) - previously postnasal drip syndrome. Other causes of chronic cough include post viral cough, cough in patients with chronic obstructive pulmonary diseases, cough induced by ACE inhibitor therapy and cough in lung cancer patients (Chung et al., 2003).

A single cause of cough in a patient is less common than multiple causes of cough. In a study performed by Palombini et al. (1999) they found that asthma, CUAS, GERD either alone or in combination, were responsible for $93.6 \%$ of the cases of chronic cough. These three conditions were so frequent that they suggested the use of the term "pathogenic triad of chronic cough". $38.5 \%$ of the patients investigated had a single cause of cough, while 61.5 $\%$ of the patients had two or more causes of cough.

\subsection{Acute cough in children}

Some studies of acute cough are old and show systematic reviews on the natural history of the acute cough in children (35-50years). Hay and Wilson (2002) did prospective study of the period 1999-2001 of acute cough, which displayed that within 10 days $50 \%$ of the children showed recovery, and 90\% within 25 days. Also an Australian prospective community study recorded respiratory episodes of 2.2-5.3 year for children aged $\leq 10$ years, with results showing a mean duration of 5.5-6.8 days of the episodes (Leder et al., 2003). Thereby indicating that acute cough should be defined as cough less then 14 days of duration.

The most common etiology of acute cough in children is due to an uncomplicated viral acute respiratory tract infection, though one must exclude more serious problems as aspiration of foreign material (Chang et al., 2006).

\subsection{Chronic cough in children}

Acute cough in children is defined as cough less than 2 weeks, prolonged acute cough (subacute) 2-4 weeks, chronic cough more than 4 weeks (Chang et al., 2006). Definition of 
cough in adults is subdivided differently. Acute cough duration is of less than 3 weeks, subacute 3-8 weeks and chronic more than 8 weeks (Pratter el al., 2006; Morice et al., 2007).

Chronic cough may be classified according to its etiology. By this classification cough is divided into 'expected' cough, non-specific cough and specific cough; its scientific rationale is discussed elsewhere (Chang, 2005). In expected cough, the cough is anticipated, such as after an acute respiratory tract infection. In specific cough the cause is clearly definable by usage of history and examination, where coexisting symptoms and sign often help in diagnosing the etiology. These causes are often serious. Nonspecific cough is a dry cough where neither known aetiology nor any respiratory disease has been identified. Chronic cough in children is most commonly due to an upper respiratory tract infection, asthma, gastrointestinal reflux as well as other more uncommon causes.

\subsection{Cough reflex sensitivity assessment}

The cough reflex sensitivity can be assessed by the inhalation cough challenge test. In this test an acid or a non-acid tussive is used to induce cough experimentally. The most common non-acid tussive is capsaicin, while citric and tartaric acids are the most commonly used acid tussives. Before 2007 standardized methods did not exist, making it impossible to compare data in studies obtained from different institutions. The European Respiratory Society (ERS) developed guidelines in 2007 on the standardization of testing with tussive and non tussive tussives (Morice et al., 2007).

During the inhalation cough challenge test, the tussives can be administered either by using single-dose or the dose-response method (Morice et al., 2001). In the single-dose method, one concentration of capsaicin or citric acid is administered. In the dose-response method the tussives are administered over a prolonged period. In the dose-response method, variations in respiratory frequency and tidal volume are thought to cause variation in the amount of tussive delivered from individual to individual, and therefore accuracy and reproducibility is poor. The single dose method is the most widely used method, because of the accuracy and reproducibility of the dose delivered (Morice et al., 2007).

The inspiratory flow rate affects the pattern of distribution of the tussives in the airways. Variation in the inspiratory flow rate thus will affect the cough challenge test. The lowering the inspiratory flow rate will increase the cough response to citric acid. Controlling the flow rate ensures that the same amount of tussive is delivered to different individuals (Barros et al., 1991). To control the inspiratory flow rate, ERS currently recommend the use a compressed air-driven nebulizer controlled by a dosimeter modified by an inspiratory regulatory flow regulator valve (Morice et al., 2007).

The patient should be told not to suppress any coughs and not to talk immediately after inhalation of the tussive, since talking suppresses the cough response. The cough induced by capsaicin and citric acid occur immediately and only sustain for a short period. Therefore only coughs that occur within $15 \mathrm{sec}$ after the administration of the tussive should be counted. Any cough occurring after this interval should not be counted, since it is not likely to be induced by the tussive agent. In studies the concentration of the selected tussive agent causing two (C2) and five (C5) coughs are reported. $\mathrm{C} 2$ is the concentration first resulting in 2 or more coughs, while $\mathrm{C} 5$ is the first concentration resulting in 5 or more coughs. In patient with high cough threshold a $\mathrm{C} 5$ value may not be possible to obtain, and ERS recommend that these individuals are excluded from the clinical trials (Morice et al., 2007). 
During the cough challenge test it is also recommended to use placebo inhalations with physiological saline (Morice et al., 2001). The saline solution should be used randomly between the different concentrations of the tussive agent. This is thought to decrease voluntary suppression of cough (Morice et al., 2007).

Tachyphylaxis is the process in which the effect of a drug is reduced during continuous use or by constantly repeated drug administration. In one study that used continuous inhalation over $1 \mathrm{~min}$ with capsaicin, the cough frequency was reduced by one third. In continuous inhalation with citric acid, no coughs were evoked after the 1 min period (Morice et al., 1992). The ERS recommends an interval between cough challenge measurements of minimally 1 hour. The optimal interval is set by the ERS to 2 hours.

No serious adverse effect is associated with cough challenge testing using capsacin as tussive agent. The most commonly reported side effect is transient throat irritation (Morice et al., 2007).

Citric acid inhalation may result in a small reduction of forced expiratory volume (FEV), but this is thought to be without clinical significance (Laude et al., 1993). Capsaicin induces bonchoconstriction, but it is not tough to have clinical significance in healthy individuals or in individuals with asthma bronchiale. However, ERS recommend that bronchodilators should be easily available when a cough challenge test is performed (Morice et al., 2007).

\section{Cough in rhinosinusitis}

Rhinitis refers to inflammation of the nasal mucosa, while sinusitis means inflammation of the mucosa in one or more of the paranasal sinuses. A continuum exists between rhinitis and sinusitis owing to the anatomical and physiological relationship of the nose and paranasal sinuses. Sinus inflammation generally develops in association with rhinitis and the term rhinosinusitis is applied to these disorders (Probst et al., 2005). Chronic rhinosinusitis is among the commonest causes of chronic cough in adults. In $20-40 \%$ of patients with chronic cough who have normal chest $\mathrm{x}$-ray, chronic rhinosinusitis is reported to be the cause of the cough (Tatar et al., 2009).

Chronic rhinosinusitis may be caused by diseases of a chronic inflammatory, allergic, traumatic or neoplastic nature. Chronic rhinosinusitis may also develop as a result of anatomical changes, as seen in e.g. septal deviation or septal spurs. Impaired ventilation of the ostiomeatal unit caused by obstruction or stenosis is the common mechanism for development of rhinosinusistis. The obstruction impairs drainage from the sinus systems. The drainage is further impaired by swelling of the mucosa in the narrow anatomical canal of the ostiomeatal unit. A viscous circle of recurrent acute inflammations that develops into a chronic inflammation is established. In adults the maxillary and ethmoid cells are the sinuses most commonly affected (Probst et al., 2005).

The mechanism of chronic cough in rhinosinusitis is until now not completely understood. Chronic upper cough syndrome, previously postnasal drip, cough reflex hypersensitivity and aspiration of secretions are among the mechanisms thought to be responsible, either alone or in combination (Tatar et al., 2009).

The cough is produced by stimulation of the pharyngeal nerve endings, which are branches of the vagus nerve. The stimulation occur secondary to secretion from the nose and sinuses dripping into the hypopharynx, a process known as postnasal drip (Palombini $\mathcal{E}$ Araujo, 2003). However, only some of the patients with postnasal drip complain of cough, and some 
patients with chronic cough caused by rhinosinusitis do not experience postnasal drip. Therefore it is unlikely that postnasal drip is the only mechanism responsible for cough in nasal disease (Tatar et al., 2009). Cough reflex sensitization is often observed in patients with chronic cough, including those with nasal diseases. The cough reflex cannot be triggered from the nose, but cough reflex sensitization may occur in nasal diseases. Tatar et al. (2009) have suggested that central sensitization of the cough reflex mediated by the nasal trigeminal sensory nerves may be one of the possible mechanisms of chronic cough in patients with nasal diseases. Chronic cough in nasal diseases may also be secondary to aspiration of secretions. The secretions are thought to stimulate the vagal afferents in the lung, thereby mediating cough. However more evidence is needed before this last mentioned mechanism can be accepted as a mechanism of cough in nasal diseases (Pratter, 2006).

The diseases of the nose and paranasal sinuses are among the most commonly identified causes of chronic cough (Pratter, 2006). Depending on the population studied and the variations in diagnostic algorithm, the diseases of nose and sinuses are reported to contribute to coughing in $20-40 \%$ of patients with chronic cough who have normal chest radiograph (Chung $\mathcal{E}$ Pavord, 2008). The mechanisms of chronic cough in rhinosinusitis are incompletely understood. Several mechanisms have been proposed, single or in combination: postnasal drip (PND), direct irritation, inflammation in the lower airways and the cough reflex sensitization (Pratter, 2006).

\subsection{Cough reflex hypersensitivity}

Cough reflex hypersensitivity refers to a condition in which the cough reflex is more readily inducible. Cough reflex hypersensitivity can be demonstrated as 1) the lowered intensity of a stimulus required to trigger cough or 2) enhanced coughing in response to a stimulus with the constant intensity. In clinical and laboratory experiments, the cough reflex hypersensitivity is detected by measuring the cough threshold or by evaluating changes in the number of coughs induced by a stimulus with defined intensity. The cough threshold is measured by a controlled inhalation of increasing concentrations of an aerosolized tussigen, commonly capsaicin or acidic solutions (Morice et al., 1997) and (Choudry \& Fuller, 1992). The cough threshold is defined as the lowest concentration of the tussigen required to induce a predetermined number of coughs (typically 2 and 5 coughs, denoted $C_{2}$ and $C_{5}$, respectively). The cough reflex hypersensitivity is found when the cough threshold in the patient group is lower than in the appropriate reference group.

The cough reflex hypersensitivity is often reported in patients with chronic cough attributed to disparate causes including nasal diseases (McGarvey et al., 1998). It is implied that the cough reflex hypersensitivity contributes to coughing. In patients with a sensitized cough reflex, the environmental and endogenous stimuli are predicted to be more effective to trigger cough. Thus the cough reflex hypersensitivity results in the amplification of cough, similar to the amplification of pain in hyperalgesia. The observations that the cough sensitivity decreases with the successful treatment or natural resolution of cough also support the notion that the cough sensitization contributes to coughing (McGarvey et al., 1998, O'Connell et al., 1994, O'Connell et al., 1996).

There is a consensus that the cough reflex cannot be triggered from the nose. There is the mechanistic question whether the cough reflex can be sensitized from the nose. Based on the general concept that the activation of nasal sensory nerves leads to cough reflex 
hypersensitivity, a series of studies in humans and in animal models were carried out (Tatar et al., 2009).

\subsection{Sensory nerve activators in the nose sensitize the cough reflex}

The hypothesis that the afferent nerve activators applied into the nose sensitize the cough reflex in humans by using sensory activators histamine and capsaicin was aevaluated. Histamine is a prototypic mediator of nasal inflammation that directly stimulates a subset of nasal sensory nerves (Taylor-Clark et al., 2005). The TRPV1 selective agonist capsaicin is also an efficient activator of the nasal sensory nerves (Taylor-Clark et al., 2005). A large proportion of the TRPV1-positive trigeminal neurons innervating the nose express a variety of receptors relevant for detection of stimuli associated with inflammation. For example, nasal trigeminal neurons functionally express the histamine $\mathrm{H} 1$ receptor, the leukotriene cys-LT 1 receptor (Taylor-Clark et al., 2005; Taylor-Clark et al., 2008a, Taylor-Clark et al., 2008b). Intranasal administration of capsaicin likely stimulates large proportion of nerves that are also stimulated or modulated by nasal inflammation. Local and reflex consequences of the sensory nerves activation with histamine and capsaicin (such as substance P release from peripheral terminals and reflex vasodilation) may generate additional stimuli that further stimulate nasal sensory nerves (Tani et al., 1990; Petersson et al., 1989). In addition, direct effects of histamine on the cells other than sensory nerves likely lead to generation of more endogenous sensory stimuli.

Consistent with the extensive data from human studies (Philip et al., 1994; Secher et al., 1982) intranasal administration of histamine and capsaicin failed to trigger cough in healthy subjects (Plevkova et al., 2004; Plevkova et al., 2006). The effective activation of nasal sensory nerves by histamine and capsaicin was confirmed by the occurrence of sensations and symptoms typically described after intranasal administration of these agents. The cough was induced by inhalation of a tussigen aerosol during the time window of the most pronounced nasal symptoms evaluated by a composite score.

Both histamine and capsaicin applied into the nose caused sensitization of the cough reflex in healthy subjects (Plevkova et al., 2004; Plevkova et al., 2006). Following the intranasal administration of capsaicin or histamine, the number of coughs induced by inhalation of a defined dose of capsaicin was increased by $60-80 \%$. Similarly, intranasal histamine did not trigger cough but sensitized the cough reflex in patients with allergic rhinitis (Plevkova et al., 2005). These data are consistent with the hypothesis that the activation of nasal sensory nerves sensitizes the cough reflex (Tatar et al., 2009).

\subsection{Cough reflex is sensitized in patients with allergic rhinitis}

The cough reflex hypersensitivity in patients with allergic rhinitis was evaluated (Pecova et al., 2005; Pecova et al., 2008). Chronic nasal symptoms attributable to sensory nerve activation in patients with rhinitis implicate that the inflammation leads to repeated activation of sensory nerves. The repeated activation and mediators associated with inflammation can induce sensitization at multiple levels of sensory pathways. Thus we predicted that the cough reflex is more sensitive in patients with allergic rhinitis than in healthy subjects (Pecova et al., 2005; Pecova et al., 2008, Tatar et al., 2009).

The grass pollen-sensitive patients with allergic rhinitis were studied out of pollen season. All patients included in the studies were free of nasal symptoms at the time of investigation. We found that the cough reflex was more sensitive in patients with allergic rhinitis 
compared to healthy subjects (measured by the capsaicin $\mathrm{C}_{2}$ cough threshold) (Pecova et al., 2005). This finding was reproduced in a separate study in which the capsaicin $C_{5}$ threshold was evaluated in another groups of patients and healthy subjects (Pecova et al., 2008). In this study, the concentrations of capsaicin causing five coughs $\left(\mathrm{C}_{5}\right.$, geometric mean and $\left.95 \% \mathrm{CI}\right)$ were 132.4 (41.3-424.5) $\mu \mathrm{M}$ and $13.1(6.0-28.6) \mu \mathrm{M}$ in healthy subjects (5 M/7F, mean age 23 yrs) and patients with allergic rhinitis $(5 \mathrm{M} / 7 \mathrm{~F}$, mean age $23 \mathrm{yrs})$, respectively $(P<0.05)$. We conclude that the cough reflex is sensitized in patients with allergic rhinitis (Pecova et al., 2008).

Since the symptoms of allergic rhinitis in pollen-sensitive patients are most prominent during the pollen season, we hypothesized that the sensitization of cough is most pronounced in this period. Fifteen patients were evaluated out of pollen season (JanuaryFebruary) and in the grass pollen season (May-June) in a paired study(Pecova et al., 2005). The capsaicin cough $\mathrm{C}_{2}$ threshold was reduced in the pollen season vs. out of the pollen season, $0.11(0.3-0.33) \mu \mathrm{M}$ vs. $0.84(0.14-5.2) \mu \mathrm{M}$, respectively $(P<0.05)$. Thus the cough reflex in patients with allergic rhinitis is further sensitized in the period when the nasal inflammation is more active.

\subsection{Sensitized cough reflex and coughing in humans}

In a series of studies it was demonstrated that the cough reflex in healthy subjects is sensitized by the intranasal administration of sensory nerve activators (Plevkova et al., 2004; Plevkova et al., 2006). These results are consistent with the hypothesis that the activation of nasal sensory nerves sensitizes the cough reflex (Tatar et al., 2009). We also show that the cough reflex is sensitized in patients with allergic rhinitis Pecova et al., 2005; Pecova et al., 2008, Tatar et al., 2009) and is further sensitized in this group by intranasal sensory activator histamine (Plevkova et al., 2005) and during the period of more active nasal inflammation (Pecova et al., 2005). Our results may help to explain the mechanisms contributing to chronic cough associated with rhinosinusitis (Tatar et al., 2009).

These results are highly indicative that nasal sensory nerves are the neural pathways involved in the sensitization of cough. The wealth of data from the somatosensory (Jiand $\mathcal{E}$ Woolf, 2001) and vagal (Mazzone et al., 2005; Mazzone E Canning, 2002) systems allows for an informed speculation that central cough reflex hypersensitivity mediated by nasal sensory nerves underlies the observed cough sensitization. In this scenario the afferent inputs from the nose feed into the central regulatory circuits of the cough reflex in a manner rendering the cough reflex hypersensitive. It has been demonstrated that the cough reflex triggered from trachea is sensitized by the stimulation of sensory nerves innervating distal parts of the respiratory system (lungs) in animal models (Mazzone and Canning, 2005), or even from the esophagus in humans (Javorkova et al., 2008). The sensitization of cough by the nasal trigeminal sensory pathways is perhaps more complex than the vagally mediated sensitization, since the trigeminal and the cough-triggering vagal sensory nerves terminate in different areas of the brainstem. Interestingly, the sensitization of cough from the nose can be induced even in anaesthetized animals, suggesting that the cough sensitization does not require intact cortical function.

The situation is more complex in patients with allergic rhinitis. Our data discussed thus far predict that the cough reflex hypersensitivity mediated by acute sensory nerve activation occurs in the symptomatic patients. However, in the patients without symptoms (such as the patients with allergic rhinitis out of the allergen season) the absence of the symptoms 
indicates limited nasal sensory activity. Yet the cough reflex is strongly sensitized in this group (Pecova et al., 2005; Pecova et al., 2008, Tatar et al., 2009). It seems unlikely that the nasal sensory nerves in patients without symptoms are stimulated in a manner that is sufficient to maintain the cough sensitization but insufficient to trigger the symptoms. Rather, we speculate that the cough sensitization is induced by sensory activation during the period with symptoms and then outlasts the sensory activation. Inflammatory mediators, neurotrophic factors and other signals emanating from the nose during symptomatic period could, in theory, initiate long-lasting neural plastic changes in the circuits regulating the cough reflex (Chen et al., 2001; Bonham et al., 2006). Mechanistic studies are needed to evaluate this speculation.

Nasal provocation with histamine induces significantly stronger sneezing responses in subjects with allergic rhinitis compared with healthy subjects - a sensitized sneezing reflex (Gerth Van Wijk \& Dieges, 1987; Sanico et al., 1999). We noted that intranasal histamine was more effective in reducing the capsaicin cough threshold in patients with allergic rhinitis than in healthy subjects (Plevkova et al., 2004; Plevkova et al., 2005). The simplest explanation is that the nasal sensory nerve pathways are sensitized, resulting in increased sensory feeding into the cough and sneeze regulatory areas. It is noteworthy in this context that nasal inflammation induces lasting changes in expression of molecules predicted to positively regulating activation and excitability in nasal afferent nerves ( $O^{\prime}$ Hanlon et al., 2007; Keh et al., 2008). However, a separate sensitization of cough and sneezing at the higher regulatory levels of cough and sneezing reflexes is also a viable option.

Another explanation is that the cough reflex is sensitized in patients with allergic rhinitis because of allergic inflammation in the lower airways and lungs. This possibility cannot be excluded. Numerous studies have shown that the inflammation in the lower airways and lungs in patients with allergic rhinitis is in many aspects similar to that in asthmatics (exemplified by Braunstahl et al., 2003). However, the studies in asthmatics failed to consistently show lowered capsaicin or citric acid cough thresholds (Fujimura et al., 1992; Chang et al., 1997; Schmidt et al., 1997). Since this is in contrast with the dramatic sensitization of cough in allergic rhinitis, this mechanism likely plays only a limited role.

Allergic rhinitis was chosen as a model of a well-defined nasal inflammation allowing for selection of a relatively homogeneous patient population (skin prick test pollen-sensitive patients). Although the cough reflex was sensitized in allergic rhinitis, none of the patients complained about coughing. The increased cough reflex sensitivity is consistently found in patients with chronic cough and the effective treatment of cough is accompanied by normalization of the cough hypersensitivity. These observations advanced the hypothesis that the cough reflex hypersensitivity is the mechanism causing the cough. However, the cough reflex hypersensitivity has been also reported in other groups of patients who do not suffer from chronic cough. For example, the cough reflex sensitivity to capsaicin is increased in the GERD patients who do not complain about cough (Benini et al., 2000; Ferrari et al., 2005). Interestingly, the magnitude of the cough threshold reduction in the GERD patients is comparable to that found in chronic coughers, and the cough threshold reduction in allergic rhinitis appears to be even larger. The cough hypersensitivity without cough was also found in other diseases (Pecova et al., 2003a; Pecova et al., 2003b).

The observations that the cough reflex hypersensitivity is not always accompanied by cough force the conclusion that the cough reflex hypersensitivity alone is not sufficient for clinical presentation of chronic cough. Rather, the increased cough reflex sensitivity contributes to 
chronic cough by amplifying the cough triggered by endogenous and, perhaps less likely, environmental stimuli. While the cough reflex sensitivity is predicted to worsen the cough, it is unlikely to be its only causal mechanism (Tatar et al., 2009).

\subsection{Potential mechanisms triggering cough in patients with rhinosinusitis and cough}

The cough reflex hypersensitivity is predicted to amplify cough by increasing the efficiency of endogenous and environmental stimuli to trigger cough but is unlikely to cause chronic coughing by itself. There is an ongoing discussion in the literature whether diseases of the nose actually trigger cough (Morice, 2004; Sanu E Eccles, 2008). This confusion is also reflected in the recommendation of the term upper airway cough syndrome (UACS) to be used when discussing cough that is associated with upper airway conditions (Pratter, 2006). One proposed mechanism for triggering cough in rhinosinusitis is the postnasal drip (drainage of secretions from the nose or paranasal sinuses into the pharynx). In this scenario the cough-triggering nerves located in the hypopharynx or larynx are stimulated by secretions emanating from the nose and/or sinuses dripping down into these areas (Irwin et al., 1984). The arguments against postnasal drip as a sole cause of cough in rhinosinusitis are twofold. Postnasal drip is a common phenomenon, and only a small fraction of patients with the postnasal drip also complain about cough (O’Hara $\mathcal{E}$ Jones, 2006). Conversely, a proportion (reported $\sim 20 \%$ ) of patients with chronic cough attributed to rhinosinusitis do not experience postnasal drip. It seems therefore unlikely that postnasal drip is the exclusive mechanism triggering cough. Cough in rhinosinusitis could be also conceivably triggered by aspirated secretions stimulating cough receptors in the lower respiratory tract; however, there are limited data to support this mechanism (Pratter, 2006). As is the case with postnasal drip, the aspiration or inhalation of nasal secretions likely occurs also in patients who do not have chronic cough. Enhanced sensitivity to environmental factors has also been linked to chronic cough in rhinosinusitis (Millquist $\mathcal{E}$ Bende, 2006).

The analysis of the mechanisms triggering cough in rhinitis is further complicated by the fact that rhinosinusitis often coexists with other common causes of chronic cough such as gastroesophageal reflux disease and eosinophilic airway diseases including asthma. Thus the potential cough triggers may be unrelated to the nasal disease (discussed elsewhere in this issue). Rhinitis is also very often part of the asthma presentation (Togias, 2003) and chronic sinusitis and postnasal drip can be caused or worsen by gastroesophageal reflux (Poelmans \& Tack, 2005) introducing even more complexity into the analysis.

Treatment aimed at rhinosinusitis improves chronic cough in many patients who also present with other conditions potentially causing chronic cough (i.e. asthma or GERD). That the rhinosinusitis causes cough reflex hypersensitivity may explain the beneficial effect of this therapy. We speculate that the cough reflex hypersensitivity in combination with one or more cough triggers results in some unfortunate individuals in clinically relevant coughing termed chronic cough associated with rhinitis (Tatar et al., 2009).

\section{References}

Advenier, C. $\mathcal{E}$ Emonds-Alt, X. (1996). Tachykinin receptor antagonists and cough. Pulm Pharmacol, Vol.9, No 5-6, pp. 329-33.

Armstrong, D.J. \& Luck, J.C. (1974). A comparative study of irritant and type J receptors in the cat. Respir Physiol, Vol.21, pp. 47-60. 
Atzori, L., Bannenberg, G., Corriga, A.M., Lou, Y.P., Lundberg, J.M., Ryrfeldt, A. E Moldeus, P. (1992). Sulfur dioxide-induced bronchoconstriction via ruthenium redsensitive activation of sensory nerves. Respiration, Vol.59, pp. 272-278.

Baluk, P., Nadel, J.A. \& McDonald, D.M. (1992). Substance P-immunoreactive sensory axons in the rat respiratory tract: a quantitative study of their distribution and role in neurogenetic inflammation. J Comp Neurol, Vol.319, pp. 586-598.

Barnes P.J. (2001). Neurogenic inflammation in the airways. Respir Physiol, Vol.125, pp. 14554.

Barros, M.J., Zammattio, S.L. E Rees, P.J. (1991) Effect of changes in inspiratory flow rate on cough responses to inhaled capsaicin. Clin Sci (Lond), Vol.81, pp. 539-532.

Benini, L., Ferrari, M., Sembenini, C., Olivieri, M., Micciolo, R., Zuccali, V., Bulighin, G.M., Fiorino, F., Ederle, A., Cascio, V.L. E Vantini I. (2000). Cough threshold in reflux oesophagitis: influence of acid and of laryngeal and oesophageal damage. Gut, Vol.46, pp. 762-767.

Bergren, D.R. E Sampson, S.R. (1982). Characterization of intrapulmonary, rapidly adapting receptors of guinea-pigs. Resp Physiol, Vol.47, pp. 83-95.

Bergren, D.R. (1997). Sensory receptor activation by mediators of defense reflexes in guineapig lungs. Respir Physiol, Vol.108, pp. 195-204.

Bolser, D.C., DeGennaro, F.C., O’Reilly, S., McLeod, R.L. E Hey, J.A. (1997). Central antitussive activity of the NK1 and NK2 tachykinin receptor antagonists, CP-99,994 and SR 48968, in the guinea-pig and cat. Br J Pharmacol, Vol.121, pp. 165-70.

Bolser, D.C., Hey, J.A. \& Chapman R.W. (1999) Influence of central antitussive drugs on the cough motor pattern. J Appl Physiol, Vol.86, pp. 1017-24.

Bonham, A.C., Kott, K.S., Ravi, K., Kappagoda, C.T. E Joad, J.P. (1996). Substance P contributes to rapidly adapting receptor responses to pulmonary venous congestion in rabbits. J Physiol, Vol.493, pp. 229-38.

Bonham,, A.C., Sekizawa, S., Chen, C. E Joad, J.P. (2006). Plasticity of brainstem mechanisms of cough. Respir Physiol Neurobiol, Vol.152, pp. 312-319.

Braunstahl, G.J., Fokkens, W.J., Overbeek, S.E., KleinJan, A., Hoogsteden, H.C. E Prins, J.B. (2003). Mucosal and systemic inflammatory changes in allergic rhinitis and asthma: a comparison between upper and lower airways. Clin Exp Allergy, Vol.33, pp. 579587.

Canning, B.J. \& Mazzone, S.B. (2005). Afferent pathways regulating the cough reflex. In: Redington AE, Morice AH(eds). Acute and chronic cough. Taylor \& Francis. Boca Raton, USA, 2005, pp. 25-48 ISBN 978-0-8247-5958-2.

Canning, B.J. (2008). The cough reflex in animals: Relevance to human cough research. Lung, Vol.186 (suppl 1), pp. 23-28.

Canning, B.J., Reynolds, S.M. E Mazzone, S.B. (2001). Multiple mechanisms of reflex bronchospasm in guinea pigs. J Appl Physiol, Vol.91, pp. 2642-2653.

Canning, B.J., Reynolds, S.M., Meeker, S. \& Undem, B.J. (2000). Electrophysiological identification of tracheal $(\mathrm{T})$ and laryngeal(LX) vagal afferents mediating cough in guniea-pigs(GP). Am J Respir Crit Care Med, Vol.161, p. A434.

Carr, M.J. \& Undem, B.J. (2001). Ion channels in airway afferenet neurons. Respir Physiol, Vol.125, No.1-2, pp. 83-97. 
Carr, M.J., Hunter, D.D., Jacoby, D.B. E Undem, B.J. (2002). Expression of tachykinin in nonnociceptive vagal afferent neurons during raspiratory tract viral infection in guinea pigs. Am J Respir Crit Care Med, Vol.165, pp. 1071-5.

Caterina, M.J. \& Julius, D. (2001). The vanilloid receptor: a molecular gateway to the pain pathway. Annu Rev Neurosci, Vol.24, pp. 487-517.

Chang, A.B. (2005). Defining the cough spectrum ad reviewing the evidence for treating non-specific cough in children. Curr Pediatr Rev; Vol.1, pp. 283-296.

Chang, A.B., Landau, L.I., Van Asperen, P.P., Glasgow, N.J., Robertson, C.F., Marchant, J.M. $\mathcal{E}$ Mellis, C.M. (2006). Cough in children: definitions and clinical evaluation, Position statement of the Thoracic Society of Australia and New Zealand. MJA, Vol.184, pp. 398-403.

Chang, A.B., Phelan, P.D., Sawyer, S.M., Del Brocco, S. \& Robertson, C.F. (1997). Cough sensitivity in children with asthma, recurrent cough, and cystic fibrosis. Arch Dis Child, Vol.77, pp. 331-334.

Chen, C.Y., Bonham, A.C., Schelegle, E.S., Gershwin, L.J., Plopper, C.G. E Joad, J.P. (2001). Extended allergen exposure in asthmatic monkeys induces neuroplasticity in nucleus tractus solitarius. J Allergy Clin Immunol, Vol.108, pp. 557-562.

Choudry, N.B. \& Fuller, R.W. (1992). Sensitivity of the cough reflex in patients with chronic cough. Eur Respir J, Vol.5, No.3, pp. 296-300.

Choudry, N.B., Fuller, R.W. E Pride, N.B. (1989). Sensitivity of the human cough reflex:effect of inflammatory mediators prostaglandin E2, bradykinin, and histamine. Am Rev Respir Dis, Vol.140, pp. 137-41.

Christian, E.P. E Togo, J.A. (1995). Excitable properties and underlying $\mathrm{Na}^{+}$and $\mathrm{K}^{+}$currents in neurons from the guinea-pig jugular ganglion. J Auton Nerv Syst, Vol.56, No.1-2, pp. 75-86.

Chuang, H.H., Prescott, E.D., Kong, H., Shields, S., Jordt, S.E., Basbaum, A.I. et al. (2001). Bradykinin and nerve growth factor release the capsaicin receptor from PtdIns(4,5)P2-mediated inhibition. Nature, Vol.411, pp. 957-62.

Chung, K.F. E Pavord, I.D. (2008). Prevalence, pathogenesis, and causes of chronic cough. Lancet, Vol. 371, No.9621, pp. 1364-74.

Chung, K.F. (2003). Measurment and assessment of cough. In Cough: Causes, mechanisms and therapy. Edited by: Chung F, Widdicombe J, Boushey H. UK: Blackwell Publishing, pp. 39-48.

Coleridge, J.C. \& Coleridge, H.M. (1984). Afferent vagal C-fibre innervation of the lungs and airways and its functional significance. Rev Physiol Biochem Pharmacol, Vol.99, pp. 1110.

Coryllos, P.N. (1937). Action of the diaphragm in cough. Experimental and clinical study on the human. Am J Med Sci, Vol,194, pp. 523-35.

Deep, V., Singh, M. E Ravi, K. (2001). Role of vagal afferents in the reflex effect of capsaicin and lobeline in monkeys. Respir Physiol, Vol.125, pp. 155-168.

Ferrari, M., Olivieri, M., Sembenini, C., Benini, L., Zuccali, V., Bardelli, E., Bovo, P., Cavallini, G., Vantini, I. \& Lo Cascio, V. (1995). Tussive effect of capsaicin in patients with gastroesophageal reflux without cough. Am J Respir Crit Care Med, Vol.151, pp. 557-561. 
Fischer,. A, McGregor, G..P, Saria, A., Philippin,. B. E Kummer, W. (1996). Induction of tachykinin gene and peptide expression in guinea pig nodose primary afferent neurons by allergic airway inflammation. J Clin Invest, Vol.98, No.10, pp. 2284-91.

Forsberg,. K. $\mathcal{E}$ Karlsson, J.A. (1986). Cough induced by the stimulation of capsaicinsensitive sensory neurons in counsious guinea-pigs. Acta Physiol Scand, Vol.128, pp. 319-20.

Fox, A. (2002). Airway nerves: in vitro electrophysiology. Curr Opin Pharmacol, Vol.2, No.3, pp. 278-9.

Fujimura, M., Sakamoto, S., Kamio, Y. \& Matsuda, T. (1992). Cough receptor sensitivity and bronchial responsiveness in normal and asthmatic subjects. Eur Respir J, Vol.5, pp. 291-295.

Gerth Van Wijk, R. E Dieges, P.H. (1987). Comparison of nasal responsiveness to histamine, methacholine and phentolamine in allergic rhinitis patients and controls. Clin Allergy, Vol.17, pp. 563-570.

Gold, M.S., Reichling, D.B., Shuster, M.J. \& Levine, J.D. (1996). Hyperalgesic agents increase a tetrodotoxin-resistant Na+current in nociceptors. Proc Natl Acad Sci USA, Vol.93, No.3, pp. 1108-12.

Hanacek, J. E Korpas, J. (1982). Modification of the intensity of the expiration reflex during short-term inflation of the lungs in rabbits. Physiol Bohemoslov, Vol.31, pp. 169-174.

Hanacek, J., Davis, A. \& Widdicombe, J.G. (1984). Influence of lung strech receptors on the cough reflex in rabbits. Respiration, Vol.45, pp. 161-8.

Hay, A.D. E Wilson, A.D. (2002). The natural history of acute cough in childeren aged 0-4 years in primary care: a systematic review. Br J Gen Pract, Vol.52, pp.401-409.

Ho, C.Y., Gu, Q., Hong, J.L. E Lee, L.Y. (2000). Prostaglandin E(2) enhances chemical and mechanical sensitivities of pulmonary $\mathrm{C}$ fibers in the rat. Am J Respir Crit Car Med, Vol.162, pp. 528-533.

Ho, C.Y., Gu, Q., Lin, Y.S. \& Lee, L.Y. (2001). Sensitivity of vagal afferent endings to chemical irritants in the rat lung. Respir Pysiol, Vol.127, pp. 113-24.

Hunter, D.D. E Undem, B.J. (1999). Identification and substance P content of vagal afferent neurons innervating the epithelium of the guinea-pig trachea. Am J Respir Crit Care Med, Vol.159, pp. 1943-1948.

Hunter, D.D., Castranova, V., Stanley, C. E Dey, R.D. (1998). Effects of silica exposure on substance $\mathrm{P}$ immunoreactivity and preprotachykinin mRNA expression in trigeminal sensory neurons in Fischer 344 rats. J Toxicol Environ Health, Vol.53, No.8, pp. 593-605.

Hutchings, H.A., Morris, S., Eccles, R. E Jawad, M.S. (1993). Voluntary suppression of cough induced by inhalation of capsaicin in healthy volunteers. Respir Med, Vol.87, pp. 379-382.

Irwin, R.S., French, C.L., Curley, F.J., Zawacki, J.K. \& Bennett, F.M. (1993). Chronic cough due to gastroesophageal reflux. Clinical, diagnostic, and pathogenetic aspects. Chest, Vol.104, No.5, pp. 1511-7.

Irwin, R.S., Pratter, M.R., Holland, P.S., Corwin, R.W. E Hughes, J.P. (1984). Postnasal drip causes cough and is associated with reversible upper airway obstruction. Chest, Vol.85, pp. 346-352.

Javorkova, N., Varechova, S., Pecova, R., Tatar, M., Balaz, D., Demeter, M., Hyrdel, R. E Kollarik M. (2008). Acidification of the oesophagus acutely increases the cough 
sensitivity in patients with gastro-oesophageal reflux and chronic cough. Neurogastroenterol Motil, Vol.20, pp. 119-124.

Jiand, R.R. E Woolf, C.J. (2001). Neuronal plasticity and signal transduction in nociceptive neurons: implications for the initiation and maintenance of pathological pain. Neurobiol Dis, Vol.8, pp. 1-10.

Joad, J.P., Kott, K.S. \& Bonham, A.C. (1997). Nitric oxide contributes to substance P-induced increase in lung rapidly adapting receptor activity in guinea-pigs. J Physiol, Vol.503, No.3, pp. 635-43.

Jonzon, A., Pisarri, T.E., Coleridge, J.C. \& Coleridge, H.M. (1986). Rapidly adapting receptor activity in dogs is inversely related to lung compliance. J Appl Physiol, Vol.61, pp. 1980-7.

Karlsson, J.A. (1996). The role of capsaicin-sensitive C-fibre afferent nerves in the cough reflex. Pulm Pharmacol, Vol.9, pp. 315-21.

Keh, S.M., Facer, P., Simpson, K.D., Sandhu, G., Saleh, H.A. \& Anand, P. (2008). Increased nerve fiber expression of sensory sodium channels Nav1.7, Nav1.8, and Nav1.9 in rhinitis. Laryngoscope, Vol.118, pp. 573-579.

Klesse, L.J. \& Parada, L,F. (1999). Trks:signal transduction and intracellular pathways. Microsc Res Tech, Vol.45, No.4-5, pp. 210-6.

Kollarik, M., Dinh, Q.T., Fischer, A. E Undem, B.J. (2003). Capsaicin-sensitive and insensitive vagal bronchopulmonary C-fibers in the mouse. J Physiol, Vol.551, No.3, pp. 869-879.

Korpas, J. E Tomori, Z. (1979). Cough and other respiratory reflexes, Karger, ISBN 3-8055-30072, Basel, Switzerland.

Laude, E.A., Higgins, K.S. \& Morice, A.H. (1993). A comparative study of the effects of citric acid, capsaicin and resiniferatoxin on the cough challenge in guinea-pig and man. Pulm Pharmacol, Vol., No.3, pp. 171-5.

Leder, K., Sinclair, M.I., Mitakakis, T.Z., et al. (2003). A community-based study of respiratory episodes in Melbourne, Australia. Aust N Z J Public Health, Vol. 27, pp. 399-404.

Lee, L.Y. \& Pisarri, T.E. (2001). Afferent properties and reflex functions of bronchopulmonary C-fibers. Respir Physiol, Vol.125, pp. 47-65.

Lii, Q., Fujimura, M., Tachibi, H., Myou, S., Kasahara, K. \& Yasui, M. (2001). Characterization of increased cough sensitivity after antigen challenge in guinea pigs. Clin Exp Allergy, Vol.31, No.3, pp. 474-84.

Lopshire, J.C. E Nocol, G.D. (1998). The cAMP transduction cascade mediates the prostaglandin E2 enhancement of the capsaicin-elicited current in rat sensory neurons: wholecell and single-channel studies. J Neurosci, Vol.18, No.16, pp. 608192.

Lundberg, J.M., Hokfelt, T., Martling, C.R., Saria, A. \& Cuello, C. (1984). Substance Pimmunoreactive sensory nerves in the lower respiratory tract of various mammales including man. Cell Tisse Res, Vol. 235, pp. 251-261.

Ma, Q.P. \& Woolf, C.J. (1995). Involvement of neurokinin receptors in the induction but not maintainance of mechanical allodynia in rat flexor motoneurons. J Physiol, Vol.486, pp. 769-777.

Matsumoto S. (1988). The activities of lung strech and irritant receptors during cough. Neurosci Lett, Vol.90, pp. 125-129. 
Mazzone, S.B. \& Canning, B.J. (2002). Synergistic interactions between airway afferent nerve subtypes mediating reflex bronchospasm in guinea pigs. Am J Physiol Regul Integr Comp Physiol, Vol.283, No.1, pp. R86-R98.

Mazzone, S.B., Canning, B.J. E Widdicombe, J.G. (2003). Sensory pathways for the cough reflex,. In: Chung, F., Widdicombe, J. E Boushey, H. (eds) Cough: Causes, Mechanisms ans Therapy. Oxford: Blackwell Publishing. pp. 161-171.

Mazzone, S.B., Mori, N. E Canning, B.J. (2002). Bradykinin-induced cough in counscious guinea-pigs. Am J Respir Crit Care Med, Vol.165, p. A773.

Mazzone, S.B., Mori, N. \& Canning, B.J. (2005). Synergistic interactions between airway afferent nerve subtypes regulating the cough reflex in guinea-pigs. J Physiol, Vol.569, pp. 559-573.

McAlexander, M.A., Myers, A.C. E Undem, B.J. (1999). Adaptation of guinea pigs vagal airway afferent neurones to mechanical stimulation. J Physiol, Vol.521, pp. 239-247.

McGarvey, L.P., Heaney, L.G., Lawson, J.T., Johnston, B.T., Scally, C.M., Ennis, M., Shepherd, D.R. E MacMahon, J. (1998). Evaluation and outcome of patients with chronic non-productive cough using a comprehensive diagnostic protocol. Thorax, Vol.53, pp. 738-743.

Michael, G.J. \& Priestley, J.V. (1999). Differential expression of the mRNA for the vanilloid receptors subtype 1 in cells of the adult rat dorsal root and nodose ganglia and its downregulation by axotomy. J Neurosci, Vol.19, No.5, pp. 1844-54.

Millqvist, E. E Bende, M. (2006). Role of the upper airways in patients with chronic cough. Curr Opin Allergy Clin Immunol, Vol.6, pp. 7-11.

Mohammed, S.P., Higenbottam, T.W. E Adcock, J.J. (1993). Effects of aerosol-applied capsaicin, histamine and prostaglandin E2 on airway sensory receptors in anaesthetized cats. J Physio, l Vol.469, pp. 51-66.

Morice, A.H. (2003). Epidemiology of cough. In Cough: Causes, mechanisms and therapy. Edited by: Chung F, Widdicombe J, Boushey H. UK: Blackwell;2003, pp. 11-16.

Morice, A.H. (2004). Post-nasal drip syndrome-a symptom to be sniffed at?. Pulm Pharmacol Ther, Vol.17, pp. 343-345.

Morice, A.H., Fontana, G.A., Belvisi, M.G., Birring, S.S. et al. (2007). ERS guidelines on the assessment of cough. Eur Respir J, Vol.29, pp. 1256-1276.

Morice, A.H., Higgins, K.S. \& Yeo, W.W. (1992). Adaptation of cough reflex with different types of stimulation. Eur Respir J, Vol.5, No.7, pp. 841-7.

Morice, A.H., Kastelik, J.A. $\mathcal{E}$ Thompson, R. (2001). Cough challenge in the assessment of cough reflex. Br J Clin Pharmacol, Vol.52, pp. 365-375.

Myers, A.C., Kajekar, R. \& Undem, B.J. (2002). Allergic inflammations-induced neuropeptide production in rapidly adapting afferent nerves in guniea pig airways. Am J Physiol Lung Cell Mol Physiol, Vol.282, pp. L775-L781.

Neumann, S., Doubell, T.P., Leslie, T. E Woolf, C.J. (1996). Inflammatory pain hypersensitivity mediated by phenotypic switch in myelinated primary sensory neurons. Nature, Vol.384, pp.360-4.

Nishino, T., Sugimori, K., Hiraga, K. E Hond, Y. (1989). Influence of CPAP on reflex responses to tracheal irritation in anesthetized humans. J Appl Physiol, Vol.67, pp.954-958.

Nishino, T., Tagaito, Y. E Isono, S. (1996). Cough and the reflexes on irritation of airway mucosa in man. Pulm Pharmacol, Vol.9, pp. 485-493. 
O'Connell, F., Thomas, V.E., Pride, N.B. E Fuller R.W. (1994). Capsaicin cough sensitivity decreases with successful treatment of chronic cough. Am J Respir Crit Care Med, Vol.150, pp. 374-380.

O'Connell, F., Thomas, V.E., Studham, J.M., Pride, N.B. E Fuller R.W. (1996). Capsaicin cough sensitivity increases during upper respiratory infection. Respir Med, Vol.90, pp. 279-286.

O'Hanlon, S., Facer, P., Simpson, K.D., Sandhu, G., Saleh, H.A. \& Anand, P. (2007). Neuronal markers in allergic rhinitis: expression and correlation with sensory testing, Laryngoscope, Vol.117, pp. 1519-1527.

O'Hara J. E Jones N.S. (2006). "Post-nasal drip syndrome": most patients with purulent nasal secretions do not complain of chronic cough. Rhinology, Vol.44, pp. 270-273.

Pack, A.I. E DeLaney, R.G. (1983). Response of pulmonary rapidly adapting receptors during lung inflation. J Appl Physiol, Vol.55, pp. 955-963.

Palombini, B.C. \& Araujo, E. (2003). Cough in postnasal drip, rhinitis and rhinosinusitis. In Cough: Causes, mechanisms and therapy. Edited by: Chung F, Widdicombe J, Boushey H. UK: Blackwell;2003, pp. 107-114.

Palombini, B.C., Villanova, C.A., Araujo, E., Gastal, O.L., Alt, D.C., Stolz, D.P. E Palombini, C.O. (1999). A pathogenic triad in chronic cough: asthma, postnasal drip syndrome, and gastroesophageal reflux disease. Chest, Vol.116, No.2, pp. 279-84.

Pecova, R., Frlickova, Z., Pec, J. \& Tatar M. (2003a). Cough sensitivity in localized scleroderma with no clinical symptoms from lower airways. J Physiol Pharmacol, Vol.54 (Suppl. 1), pp. 25-28.

Pecova, R., Frlickova, Z., Pec, J. E Tatar M. (2003b). Cough sensitivity in atopic dermatitis. Pulm Pharmacol Ther, Vol16, pp. 203-206.

Pecova, R., Vrlik, M. E Tatar M. (2005). Cough sensitivity in allergic rhinitis. J Physiol Pharmacol, Vol.56 (Suppl. 4), pp. 171-178.

Pecova, R., Zucha, J., Pec, M., Neuschlova, M., Hanzel, P. \& Tatar, M. (2008). Cough reflex sensitivity testing in seasonal allergic rhinitis patients and healthy volunteers. $J$ Physiol Pharmacol, Vol.59(Suppl 6), pp. 557-564.

Pek, W.Y. E Boushey, H.A. (2003). Cough in lower airway infections. In Cough: Causes, mechanisms and therapy. Edited by: Chung F, Widdicombe J, Boushey H. UK: Blackwell;2003, pp. 83-96.

Petersson, G., Malm, L., Ekman, R. E Hakanson, R. (1989). Capsaicin evokes secretion of nasal fluid and depletes substance $P$ and calcitonin gene-related peptide from the nasal mucosa in the rat. Br J Pharmacol, Vol.98, pp. 930-936.

Philip, G., Baroody, F.M., Proud, D., Naclerio, R.M. E Togias, A.G. (1994). The human nasal response to capsaicin. J Allergy Clin Immunol, Vol.94, pp. 1035-1045.

Plevkova, J., Brozmanova, M., Pecova, R. E Tatar M. (2006). The effects of nasal histamine challenge on cough reflex in healthy volunteers. Pulm Pharmacol Ther; Vol.19, pp. 120-127.

Plevkova, J., Brozmanova, M., Pecova, R. E Tatar M. (2005). Effects of intranasal histamine on the cough reflex in subjects with allergic rhinitis. J Physiol Pharmacol, Vol.56 (Suppl. 4), pp. 185-195.

Plevkova, J., Brozmanova, M., Pecova, R. \& Tatar, M. (2004). Effects of intranasal capsaicin challenge on cough reflex in healthy human volunteers. J Physiol Pharmacol, Vol.55 (Suppl. 3), pp. 101-106. 
Poelmans, J. \& Tack, J. (2005). Extraoesophageal manifestations of gastro-oesophageal reflux. Gut, Vol.54, pp. 1492-1499.

Pounsford, J.C., Birch, M.J. E Saunders, K.S. (1985). Effect of bronchodilators on the cough response to inhaled citric aid in normal and asthmatic subjects. Thorax, Vol.5, pp. 296-300.

Pratter, M.R. (2006). Chronic upper airway cough syndrome secondary to rhinosinus diseases (previously referred to as postnasal drip syndrome): ACCP evidencebased clinical practice guidelines. Chest, Vol.129(Suppl 1), pp. S63-71.

Pratter, M.R., Brightling, C.E., Boulet, L.P. E Irwin, R.S. (2006). An empiric integration approach to the management of cough: ACCP evidence-based clinical practice guidelines. Chest, 129, pp. 222-231.

Premkumar, L.S. E Ahern, G.P. (2000). Induction of vanilloid receptor channel activity by protein kinase C. Nature, Vol.408, pp. 985-90.

Probst, R., Grevers, G. \& Iro, H. (2005). Basic Otorhinolaryngology: A Step-by-Step Learning Guide. 1st edition. Thieme; 2005, 430 p.

Riccio, M.M., Kummer, W., Biglari, B., Myers, A.C. \& Undem, B.J. (1996c). Interganglionic segregation of distinct vagal afferent fibre phenotypes in guinea-pig airway. J Physiol, Vol.496, pp. 521-530.

Riccio, M.M., Kummer, W., Biglari, B., Myers, A.C., Undem, B.J., Pride, N.B. \& Fuller, R.W. (1996b). Interganglionic segregation of distingct agal afferent fibre phenotypes in guinea-pig airways. J Physiol, Vol.496, No.2, pp. 521-30.

Riccio, M.M., Myers, A.C. \& Undem, B.J. (1996a). Immunomodulation of afferent neurons in guinea-pig isolated airways. J Physiol, Vol.491, No.2, pp. 499-509.

Roberts, A.M., Kaufman, M.P., Baker, N.G., Brown, J.K., Coleridge, H.M. \& Coleridge, J.C. (1981). Reflex tracheal contraction induced by stimulation of bronchial C-fibers in dogs. J Appl Physiol, Vol.51, pp. 485-93.

Sanico, A.M., Koliatsos, V.E., Stanisz, A.M., Bienenstock, J. \& Togias, A. (1999). Neural hyperresponsiveness and nerve growth factor in allergic rhinitis. Int Arch Allergy Immunol, Vol.118, pp. 154-158.

Sant'Ambrogio, G. E Widdicombe, J.G. (2001). Reflexes from airway rapidly adapting receptors. Respir Physiol, Vol.125, pp. 33-45.

Sant'Ambrogio, G., Sant'Ambrogio, F.B. E Davis, A. (1984). Airways receptors in cough. Bull Eur Physiopathol Respir, Vol.20, pp. 43-47.

Sanu, A. E Eccles, R. (2008). Postnasal drip syndrome. Two hundred years of controversy between UK and USA. Rhinology, Vol.46, pp. 86-91.

Schelegle, E.S. E Green, J.F. (2001). An overview of the anatomy and physiology of slowly adapting pulmonary strech receptors. Respir Physiol, 125, pp. 17-31.

Schmidt, D., Jorres, R.A. E Magnussen, H. (1997). Citric acid-induced cough thresholds in normal subjects, patients with bronchial asthma, and smokers. Eur J Med Res, Vol.2, pp. 384-388.

Secher, C., Kirkegaard, J., Borum, P., Maansson, A., Osterhammel, P. \& Mygind, N. (1982). Significance of $\mathrm{H} 1$ and $\mathrm{H} 2$ receptors in the human nose: rationale for topical use of combined antihistamine preparations. J Allergy Clin Immunol, Vol. 70, pp. 211-218.

Shannon, R., Baekey, D.M., Morris, K.F. E Lindsey, B.G. (1997). Brainstem respiratory networks and cough. Pulm Pharmacol, Vol.9, pp. 343-7. 
Shannon, R., Baekey, D.M., Morris, K.F. E Lindsey, B.G. (1998). Ventrolateral medullary respiratory network and a model of cough motor pattern generation. J Appl Physiol, Vol.84, pp. 2020-2035.

Shannon, R., Baekey, D.M., Morris, K.F., Li, Z. \& Lindsey, B.G. (2000). Functional connectivity among ventrolateral medullary respiratory neurons and responses during fictive cough in the cat. J Physiol, Vol.525, pp. 207-24.

Shannon, R., Bolser, D.C. E Lindsey, B.G. (1996). Neural control of coughing ans sneezing. In: Miller AD, Bianchi AL, Bishop BP, eds. Neural Control of Breathing. Boca Raton: CRC Press, 1996, pp. 215-24.

Shin, J., Cho, H., Hwang, S.W., Jung, J., Shin, C.Y., Lee, S.Y. et al. (2002). Bradykinin-12lipoxygenase-VR1 signaling pathway for inflammatory hyperalgesia. Proc Natl Aced Sci USA, Vol.99, No.15, pp. 10150-5

Stead, R.H. (1992). Nerve remodelling during intestinal inflammation. Ann N Y Acad Sci, Vol.664, pp. 443-55.

Tani, E., Senba, E., Kokumai, S., Masuyama, K., Ishikawa, T. \& Tohyama M. (1990). Histamine application to the nasal mucosa induces release of calcitonin generelated peptide and substance $P$ from peripheral terminals of trigeminal ganglion: a morphological study in the guinea pig. Neurosci Lett, Vol.112, pp. 1-6.

Tatar, M., Plevkova, J., Brozmanova, M., Pecova, R. \& Kollarik, M. (2009). Mechanisms of the cough associated with rhinosinusitis. Pulm Pharmacol Ther, Vol.22, pp. 121-6.

Tatar, M., Sant'Ambrogio, G. E Sant'Ambrogio, F.B. (1994). Laryngeal and tracheobronchial cough in anesthetized dogs. J Appl Physiol, Vol.76, pp. 2672-2679.

Tatar, M., Webber, S.E. E Widdicombe, J.G. (1988). Lung C-fibre receptor activation and defensive reflexes in anaethetized cats. J Physiol, Vol.402, pp. 411-420.

Taylor-Clark, T.E., Kollarik, M., MacGlashan, D.W. Jr. E Undem B.J. (2005). Nasal sensory nerve populations responding to histamine and capsaicin. J Allergy Clin Immunol, Vol.116, pp. 1282-1288

Taylor-Clark, T.E., Nassenstein, C. \& Undem B.J. (2008a). Leukotriene D4 increases the excitability of capsaicin-sensitive nasal sensory nerves to electrical and chemical stimuli. Br J Pharmacol, Vol.154, pp. 1359-1368.

Taylor-Clark, T.E., Undem, B.J., Macglashan, D.W. Jr., Ghatta, S., Carr, M.J. \& McAlexander, M.A. (2008b). Prostaglandin-induced activation of nociceptive neurons via direct interaction with transient receptor potential A1 (TRPA1). Mol Pharmacol, Vol.73, pp. 274-281.

Togias, A. (2003). Rhinitis and asthma: evidence for respiratory system integration. J Allergy Clin Immunol, Vol.111, pp. 1171-1183.

Tomaki, M., Ichinose, M., Miura, M., Hirayama, Y., Yamauchi, H., Nakajima, N. et al. (1995). Elevated substance $\mathrm{P}$ content in induced sputum from patients with asthma and patients with chronic bronchitis. Am J Respir Crit Care Med, Vol.151, pp. 613-7.

Undem, B.J., Oh, E.J., Lee, M. E Weinreich, D. (2003). Subtypes of vagal nociceptive C-fibers in guinea pig lungs. Am J Respir Crit Care Med, Vol.167, Suppl., p. A708.

Virchow, J.C., Julius, P., Lommatzsch, M., Luttmann, W., Renz, H. E Braun, A. (1998). Neurotrophins are increased in bronchoalveolar lavage fluid after segemental allergen provocation. Am J Respir Crit Care Med, Vol.158, No.6, pp. 2002-5.

Wang, A.L., Blackford, T.L. \& Lee, L.Y. (1996). Vagal bronchopulmonary C-fibers and acute ventilatory response to inhaled irritants. Respir Physiol, Vol.104, pp. 231-239. 
Widdicombe, J.G. (1974). Pathophysiology of lung reflexes. Bull Physiopathol Respir (Nancy), Vol.10, No.1, pp. 65-9.

Widdicombe, J.G. (2001). Airways receptors. Respir Physiol, Vol.125, pp. 3-15.

Widdicombe, J.G. (2003). Overview of neural pathways in allergy and asthma. Pulm Pharmacol Ther, Vol.16, No.1, pp. 23-30.

Woolf, C.J. \& Salter, M.W. (2000). Neuronal plasticity: increasing the gain in pain. Science, Vol.288, pp. 1765-9. 


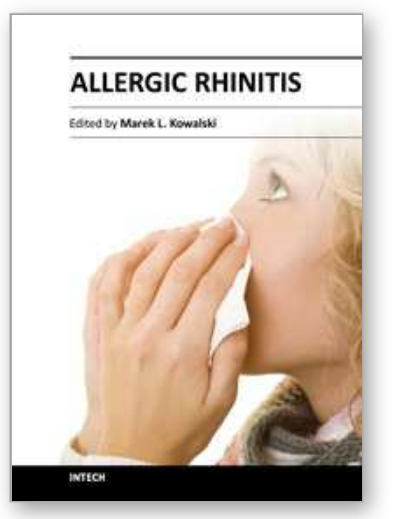

\author{
Allergic Rhinitis \\ Edited by Prof. Marek Kowalski
}

ISBN 978-953-51-0288-5

Hard cover, 214 pages

Publisher InTech

Published online 21, March, 2012

Published in print edition March, 2012

Allergic rhinitis, while troublesome for a patient, may be also a challenge for the physician. That is why physicians must still learn more on the pathophysiology, clinical spectrum and novel diagnostic and therapeutic approaches to the disease. The chapters of this volume address a variety of important topics related to allergic rhinitis. They begin with a description of innovative translational approaches allowing for unification of animal and human models. Contributing authors provide up-to-date reviews of clinical aspects of allergic rhinitis in children, its association with bronchial asthma and other co-morbid conditions. They also discuss the impact of allergic rhinitis on sleep and sports. Together with articles on diagnostic approaches as well as novel treatments, the book offers a comprehensive and stimulating review of the topic. May this book find a wide readership among allergists and other physicians interested in allergic disease, and also among pediatricians, general practitioners and other specialists who increasingly have to deal with this seemingly benign, but sometimes extremely troublesome, disease.

\title{
How to reference
}

In order to correctly reference this scholarly work, feel free to copy and paste the following:

Renata Pecova and Milos Tatar (2012). Cough in Allergic Rhinitis, Allergic Rhinitis, Prof. Marek Kowalski (Ed.), ISBN: 978-953-51-0288-5, InTech, Available from: http://www.intechopen.com/books/allergic-rhinitis/cough-inallergic-rhinitis

\section{INTECH}

open science | open minds

\section{InTech Europe}

University Campus STeP Ri

Slavka Krautzeka 83/A

51000 Rijeka, Croatia

Phone: +385 (51) 770447

Fax: +385 (51) 686166

www.intechopen.com

\section{InTech China}

Unit 405, Office Block, Hotel Equatorial Shanghai

No.65, Yan An Road (West), Shanghai, 200040, China 中国上海市延安西路65号上海国际贵都大饭店办公楼405单元

Phone: +86-21-62489820

Fax: $+86-21-62489821$ 
(C) 2012 The Author(s). Licensee IntechOpen. This is an open access article distributed under the terms of the Creative Commons Attribution 3.0 License, which permits unrestricted use, distribution, and reproduction in any medium, provided the original work is properly cited. 